\title{
Organophotoredox/Ni-Cocatalyzed Allylation of Allenes:
}

\section{Regio-, and Diastereoselective Access to Homoallylic Alcohols}

Hui Xie, and Bernhard Breit*

Institut für Organische Chemie, Albert-Ludwigs-Universität Freiburg, Albertstraße 21, 79104

Freiburg im Breisgau, Germany

E-mail: bernhard.breit@chemie.uni-freiburg.de

\begin{abstract}
A dual organophotoredox/nickel-catalyzed reductive coupling of allenes with aldehydes has been developed for the rapid assembly of anti-homoallylic alcohols with high levels of regioselectivities ( $>20: 1$ ), and diastereoselectivities (up to $>20: 1$ ) and yields (up to 91\%). The allylation was realized through a crucial $\pi$-allylnickel intermediate which was obtained via insertion of allenes with a $\mathrm{Ni}-\mathrm{H}$ intermediate. Moreover, $\mathrm{Y}, \mathrm{\gamma}$-disubstituted homoallylic alcohols with a quaternary stereocenter can also be prepared by this protocol.
\end{abstract}

Homoallylic alcohols are prevalent structural motifs found in bioactive molecules, pharmaceuticals, and versatile intermediates in organic synthesis. ${ }^{[1]}$ In light of the biological relevance and wide-ranging structural diversity of homoallylic alcohol structures, a number of synthetic strategies for their construction have been developed which can be summarized in four major methods (Scheme 1a). While carbonyl addition mediated by premetalated reagents ${ }^{[2]}$, Barbier-type allylation, continues to play an important role in this synthesis. However, the required organometallic reagents can be hazardous, frequently requires cryogenic conditions, and generates stoichiometric quantities of metallic byproducts, which are major disadvantages. Alternatively, transition-metal-catalyzed reductive couplings of $\pi$-unsaturated reagents with carbonyls refrain from the use of allylmetal reagents. ${ }^{[3]}$ Albeit, stoichiometric amounts of terminal reductants are necessary in this strategy. Despite great progress has been made, step away from reductants remain synthetically underexplored until the invention of hydrogenmediated reductive coupling of carbonyls reported by Krische and co-workers. ${ }^{[4]}$ These transformations occurred with good yields and stereoselectivities, while they need expensive precious transition-metal catalysts. From the perspective of atom-economy and synthetic efficiency, the development of a complementary catalytic platform involving inexpensive transition-metal catalysts is of utmost importance. Furthermore, the merger of photoredox catalysis with transition-metal catalysis, metallaphotoredox, has become a major topic in synthetic methodology under mild conditions over the past decade. ${ }^{[5]}$ In addition, great efforts have been devoted in nucleophilic allylation using alkenes ${ }^{[6]}$, allylacetates ${ }^{[7]}$, allylbromides ${ }^{[8]}$ and 1,3-dienes ${ }^{[9]}$ using metallaphotoredox catalysis. However, stereoselective allylation involving allenes remain underexplored.

In particular, photoredox and nickel dual catalysis gained considerable interest in the past years for the efficient construction of complex molecular structures from readily available starting materials, given the availability of various oxidation states of nickel catalysts, including $\mathrm{Ni}^{0 / / / 1 / I I I}$. [10] Additionally, Jamison pioneered the nickel-catalyzed coupling reaction involving allenes, aldehydes, and organosilanes involving a m-allylnickel intermediate. ${ }^{[11]}$ Inspired by the 
aforementioned advances, we hypothesized that $\pi$-allylnickel complexes could be generated by merging photoredox and nickel catalysis, which couple with aldehydes to form homoallylic alcohols with stereocontrol (Scheme 1b). The key challenges, however, are (1) how to control the chemoselectivity, due to allenes displaying high reactivity and rich chemistry associated with the two orthogonal $\mathrm{C}=\mathrm{C}$ bonds, (2) how to avoid the formation of linear products, ${ }^{[12]}$ and (3) how to control the diastereoselectivity. Herein, we present a reductive allylation of allenes with aldehydes enabled by a combined nickel and organophotoredox catalysis to facile access to anti-homoallylic alcohols with high levels of regio-, and diastereoselectivities under mild conditions (Scheme 1c). Specifically, in this work, organophotoredox catalyst 4-CzIPN was used and even $\gamma, \gamma$-disubstituted homoallylic alcohols with a quanternary stereocenter can also be obtained in high selectivity.

(a) Previous allylation of carbonyls access to allylic alcohols (well established)

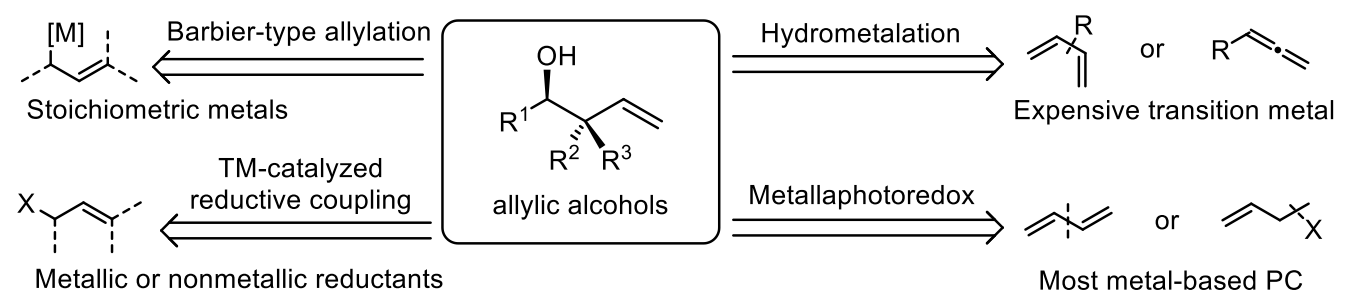

(b) Conceptual $\mathrm{Ni}-\mathrm{H}$ catalyzed allylation of allene (unexplored)

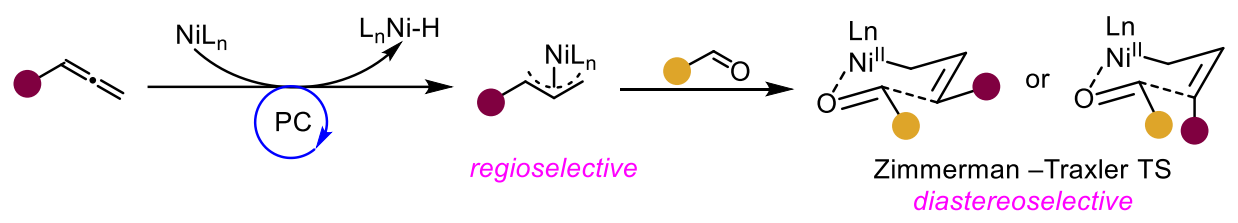

(c) Dual Ni/organophotoredox-catalyzed reductive coupling of aldehydes with allenes (This work)

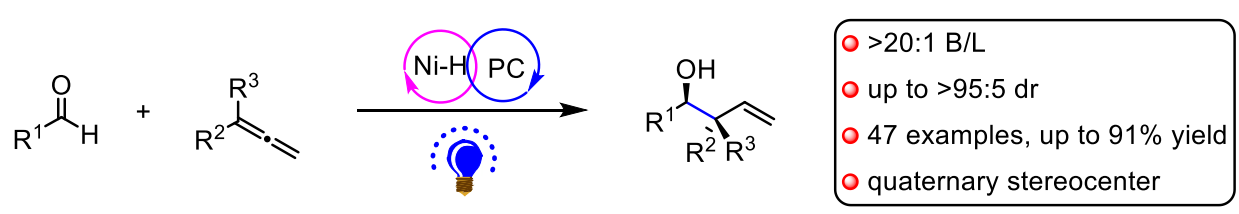

Scheme 1. Strategies for homoallylic alcohols synthesis.

Our study commenced by investigating the reductive coupling of benzaldehyde 1a and phenylallene 2a under nickel/visible-light photoredox dual catalysis. Initially, it was gratifying that the desired branched homoallylic alcohol 3a was smoothly obtained in 49\% yield with >95:5 diastereoselectivity by using $\mathrm{NiCl}_{2}$ as the catalyst, 4,4'-di('Bu)-2,2'-bipyridine (L1) as the ligand, 4-CzIPN as the organic photocatalyst, Hantzsch ester as the reducing agent, Hünig's base DIPEA as the base (Table 1, entry 1). Subsequent nickel catalyst screening revealed that $\mathrm{Ni}\left(\mathrm{NO}_{3}\right)_{2} \cdot 6 \mathrm{H}_{2} \mathrm{O}$ proved to be optimal, affording product 3a with $61 \%$ yield, $>20: 1 \mathrm{~B} / \mathrm{L},>95: 5 \mathrm{dr}$ (entries 2-4, Table S3). Further screening of photocatalysts and reductants didn't give better outcomes. It should be noted that the bipyridine ligand plays a significant role (entries 4-9, Table S4). Gladly, the yield could be further improved when electron-rich 4,4'-dimethoxyl-2,2'bipyridine (L3) was employed as the ligand (Table 1, entry 6), while other bipyridine ligands gave only moderate or low yields. 
Table 1. Reaction condition optimizations. ${ }^{[a]}$
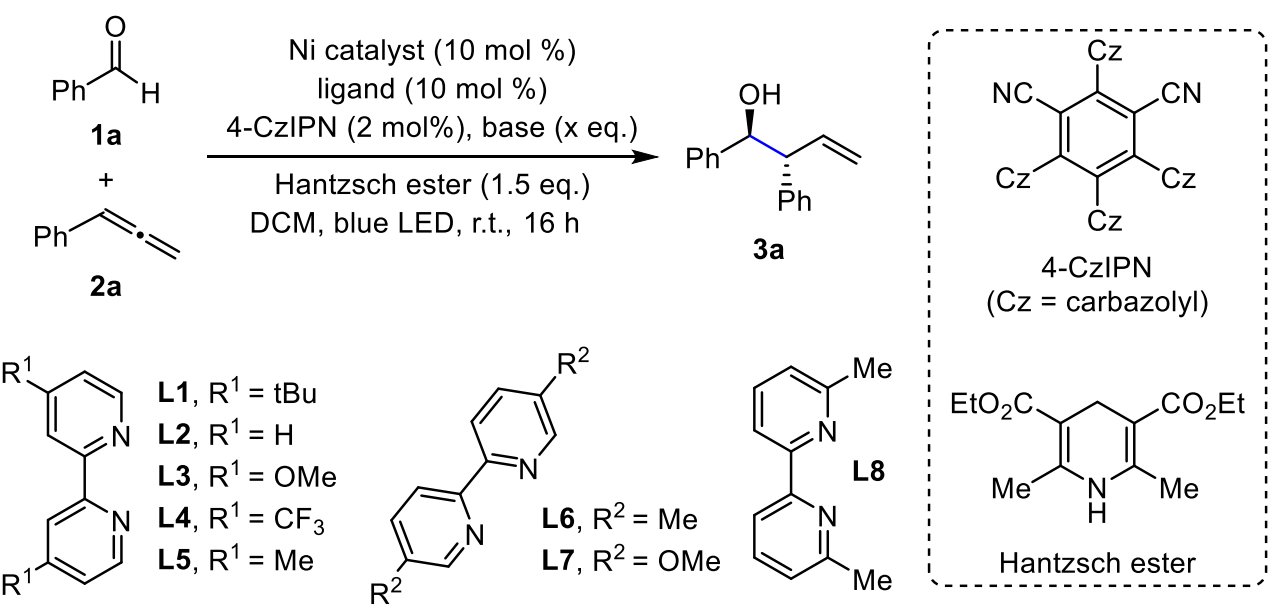

\begin{tabular}{|c|c|c|c|c|c|}
\hline entry & Ni cat. & ligand & base [eq.] & yield $/ \%[\mathrm{~b}]$ & $\mathrm{dr} / \%{ }^{[\mathrm{c}]}$ \\
\hline 1 & $\mathrm{NiCl}_{2}$ & L1 & DIPEA (2.0) & 49 & $>95: 5$ \\
\hline 2 & $\mathrm{NiCl}_{2} \cdot \mathrm{dme}$ & L1 & DIPEA (2.0) & 45 & $>95: 5$ \\
\hline 3 & $\mathrm{Ni}(\operatorname{cod})_{2}$ & L1 & DIPEA (2.0) & 34 & $>95: 5$ \\
\hline 4 & $\mathrm{Ni}\left(\mathrm{NO}_{3}\right)_{2} \cdot 6 \mathrm{H}_{2} \mathrm{O}$ & L1 & DIPEA (2.0) & $59(61)$ & $>95: 5$ \\
\hline 5 & $\mathrm{Ni}\left(\mathrm{NO}_{3}\right)_{2} \cdot 6 \mathrm{H}_{2} \mathrm{O}$ & L2 & DIPEA (2.0) & 28 & $>95: 5$ \\
\hline 6 & $\mathrm{Ni}\left(\mathrm{NO}_{3}\right)_{2} \cdot 6 \mathrm{H}_{2} \mathrm{O}$ & L3 & DIPEA (2.0) & $75(74)$ & $>95: 5$ \\
\hline 7 & $\mathrm{Ni}\left(\mathrm{NO}_{3}\right)_{2} \cdot 6 \mathrm{H}_{2} \mathrm{O}$ & L4 & DIPEA (2.0) & trace & $>95: 5$ \\
\hline 8 & $\mathrm{Ni}\left(\mathrm{NO}_{3}\right)_{2} \cdot 6 \mathrm{H}_{2} \mathrm{O}$ & L6 & DIPEA (2.0) & 60 & $>95: 5$ \\
\hline 9 & $\mathrm{Ni}\left(\mathrm{NO}_{3}\right)_{2} \cdot 6 \mathrm{H}_{2} \mathrm{O}$ & L8 & DIPEA (2.0) & 25 & $>95: 5$ \\
\hline 10 & $\mathrm{Ni}\left(\mathrm{NO}_{3}\right)_{2} \cdot 6 \mathrm{H}_{2} \mathrm{O}$ & L3 & $\mathrm{Et}_{3} \mathrm{~N}(2.0)$ & 56 & $>95: 5$ \\
\hline 11 & $\mathrm{Ni}\left(\mathrm{NO}_{3}\right)_{2} \cdot 6 \mathrm{H}_{2} \mathrm{O}$ & L3 & $\mathrm{K}_{2} \mathrm{CO}_{3}(2.0)$ & 52 & $89: 11$ \\
\hline $12^{[\mathrm{d}]}$ & $\mathrm{Ni}\left(\mathrm{NO}_{3}\right)_{2} \cdot 6 \mathrm{H}_{2} \mathrm{O}$ & L3 & DIPEA (0.5) & $79(86)^{[\mathrm{e}]}$ & $>95: 5$ \\
\hline
\end{tabular}

[a] Reaction condition (unless otherwise specified): 1 a $(0.1 \mathrm{mmol}), 2 \mathrm{a}(0.2 \mathrm{mmol})$, Ni cat. (10 mol \%), 4-CzIPN (2 mol \%), ligand (10 mol \%), Hantzsch ester (1.5 equiv.), $\operatorname{Pr}_{2} \mathrm{NEt}$ (x equiv.), $\mathrm{DCM}(1 \mathrm{~mL})$, blue LED strips, r.t. under $\operatorname{Ar}$ atmosphere for $16 \mathrm{~h}$. [b] NMR yields are reported by using 1,3,5-trimethoxybenzene as internal standard, isolated yield is presented in parenthesis. [c] Diastereoselective ratio (dr) was determined by ${ }^{1} \mathrm{H}$ NMR spectroscopy of the crude mixture. [d] Isolated yield. [e] 2a $(0.3 \mathrm{mmol})$ was used, reaction time was $15 \mathrm{~h}$. All the regioselective ratios are $>20: 1$. DIPEA $=N, N-$ Diisopropylethylamine.

Alternatively, $\mathrm{Et}_{3} \mathrm{~N}, \mathrm{~K}_{2} \mathrm{CO}_{3}$ and $\mathrm{K}_{2} \mathrm{HPO}_{4}$ could also be employed leading to the coupling product in moderate to good yields, although the diastereoselectivities were reduced (entries 10-11, Table S7). The base is considered to facilitate the transfer of protons from the oxidation of HEH to the product, due to a highly acidic environment would emerge without a proton acceptor. Decreasing the amount of DIPEA to catalytic amount ( 0.5 equiv.) can provide similar results (entry 12, Table S8). In addition, by changing the amount of allene $2 \mathrm{a}$ to 0.3 equiv. and reaction for $15 \mathrm{~h}$, we obtained the desired product $\mathbf{3 a}$ in excellent yield and diastereoselectivity (86\%, >95:5 dr) (entry 12). Finally, control experiments confirmed that photocatalyst, nickel, Hantzsch ester and blue LED are all crucial for this reductive coupling reaction (for details, please see the Supporting Information). 
Under the optimized reaction conditions, we next sought to examine the generality of the allylation of aldehydes and allenes. As shown in Table 2, a variety of different electron-rich and -poor substituents on the different positions of aryl-groups of aromatic aldehydes can be well tolerated (3a-3p), most of the desired products were obtained in good yields and high diastereoselectivity (drs). Gladly, naphthyl-, furanyl-, thiopheneyl-, and indolyl-aldehydes were also well-tolerated, regardless of the position of the substituent $(\mathbf{3 q}-\mathbf{3 v}, 79-87 \%$ yields and 91:9->95:5 drs). In addition, alkyl aldehydes can also form the desired products with good results $(3 \mathbf{w}-\mathbf{3 y})$. In order to prove the applicability of the reaction, we tried some drug and complex molecules functionalized aldehydes as substrates, and the corresponding products were obtained in moderate to good yields with good diastereoselectivities (3z-3ae).

Table 2. Substrate scope for aldehydes. ${ }^{[a]}$

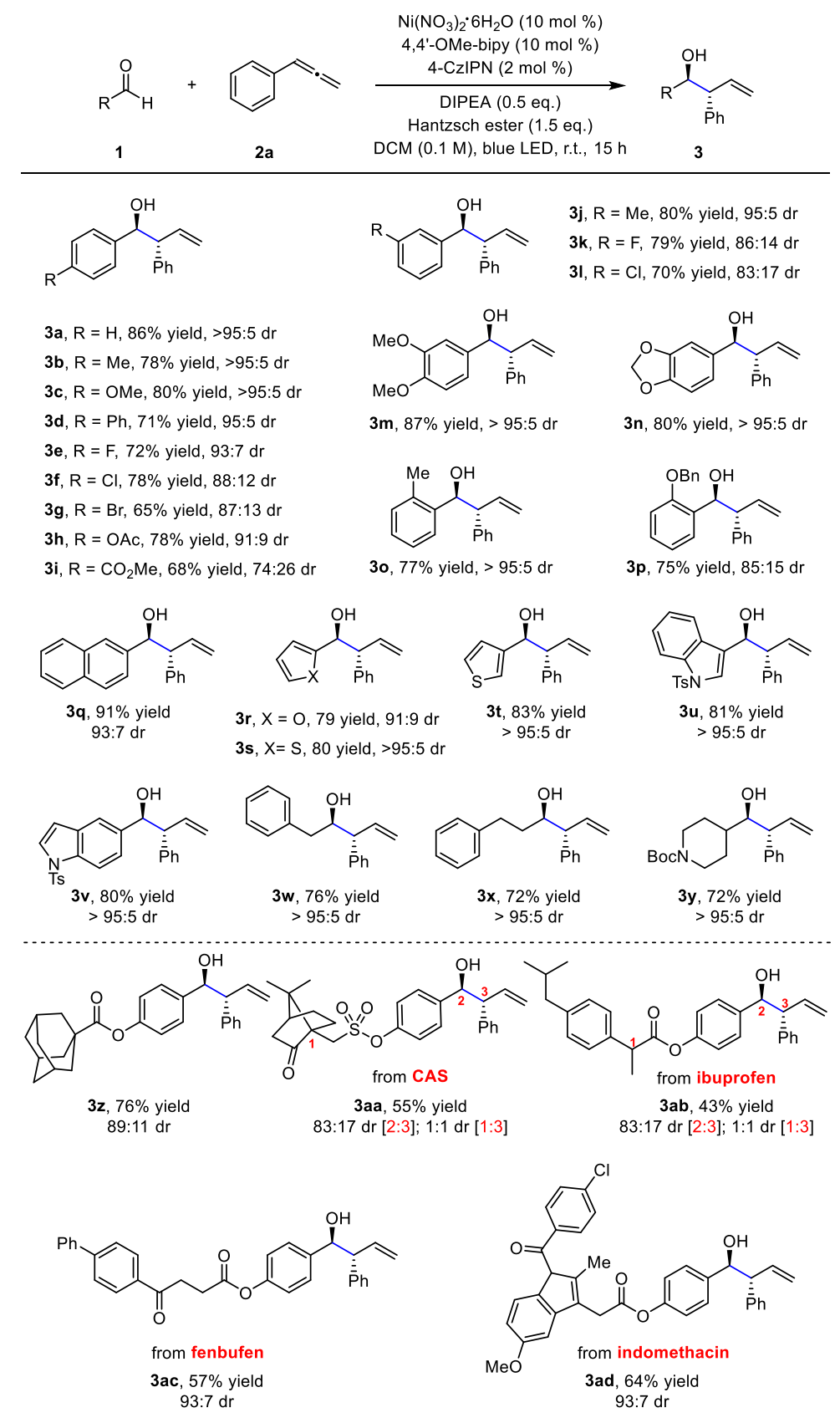


[a] Reaction condition (unless otherwise specified): $\mathbf{1}(0.2 \mathrm{mmol}), \mathbf{2 a}(0.6 \mathrm{mmol}), \mathrm{Ni}\left(\mathrm{NO}_{3}\right)_{2} \cdot 6 \mathrm{H}_{2} \mathrm{O}(10 \mathrm{~mol} \%), 4-\mathrm{CzIPN}$ (2 mol \%), L3 (10 mol \%), Hantzsch ester (1.5 equiv.), $\operatorname{iPr}_{2} \mathrm{NEt}$ (0.5 equiv.), DCM (2 mL), blue LED strips, r.t. under $\mathrm{Ar}$ atmosphere for $15 \mathrm{~h}$. Isolated yields are reported. Diastereoselective ratio (dr) was determined by ${ }^{1} \mathrm{H}$ NMR spectroscopy after purification.

Then, the scope of allenes 2 was examined (Table 3). It was found that diverse substituted allenes could be successfully converted to the homoallylic alcohols $(\mathbf{4 a - 4 j}, \mathbf{4 m})$ in good to excellent yields with high diastereoselectivities, regardless of substitution patterns or electronic properties of substituents. Particularly, alpha- and beta-substituted naphthyl-allenes were also well-tolerated (4k and $\mathbf{4 I}$ ). As expected, the alkyl allenes gave the products in lower diastereoselcetivities (4n and $\mathbf{4 0}$ ). Moreover, surprisingly, 1,1'-disubstituted allenes were amenable to this dual catalysis protocol affording the related allylation products featuring quaternary carbon centers with good yields and high diastereoselectivities (4p and $\mathbf{4 q}$ ). Unexpectedly, the internal allene $\mathbf{2 q}$ was retained and only trace amount of product was formed (4r) (see the Supporting Information).

Table 3. Substrate scope for allenes. ${ }^{[a]}$

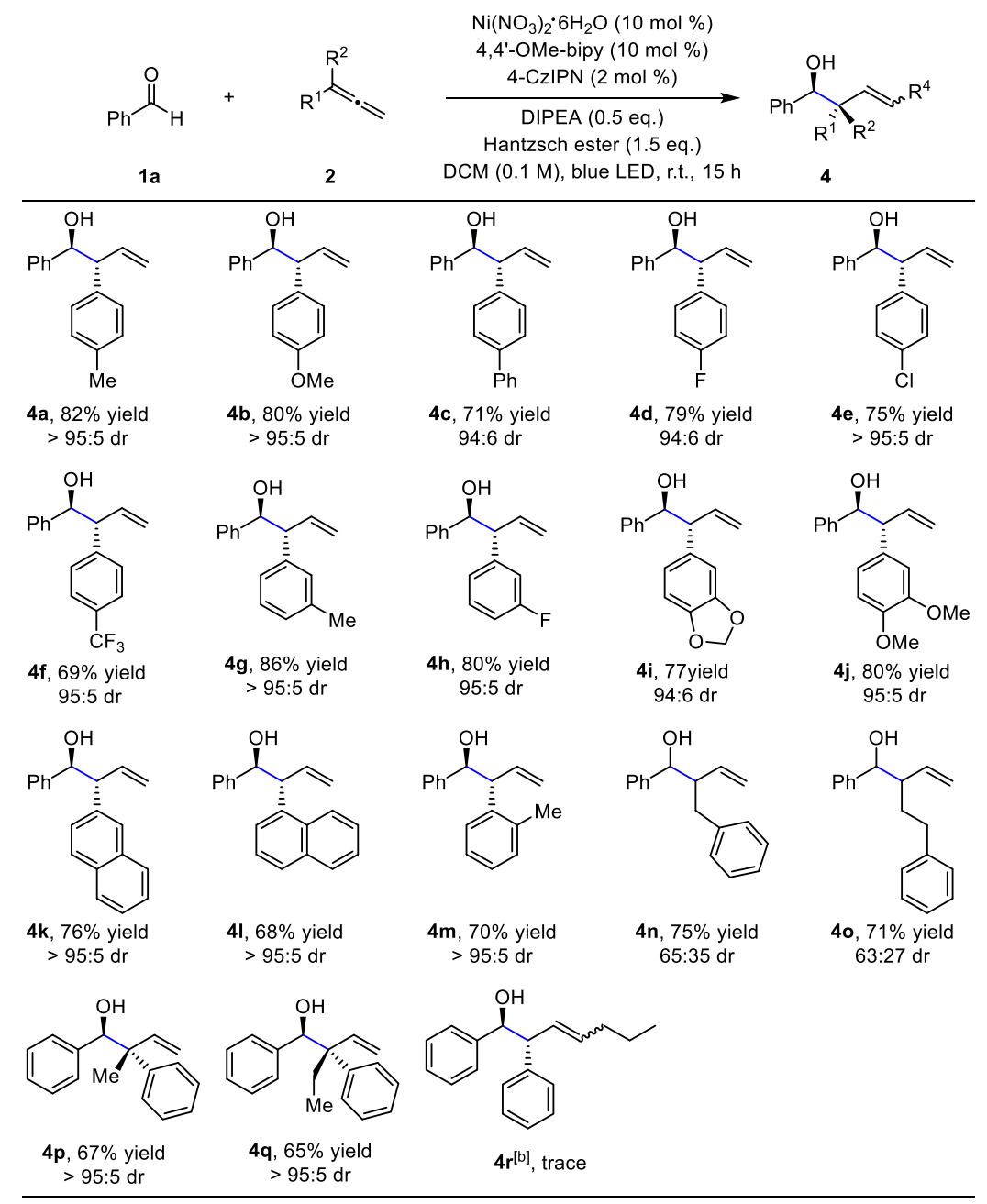

[a] Reaction condition (unless otherwise specified): $\mathbf{1 a}(0.2 \mathrm{mmol}), 2$ (0.6 mmol), Ni( $\left(\mathrm{NO}_{3}\right)_{2} \cdot 6 \mathrm{H}_{2} \mathrm{O}(10 \mathrm{~mol} \%), 4-\mathrm{CzIPN}$ (2 mol \%), L3 (10 mol \%), Hantzsch ester (1.5 equiv.), i $\operatorname{Pr}_{2} \mathrm{NEt}$ ( 0.5 equiv.), DCM (2 mL), blue LED strips, r.t. under $\mathrm{Ar}$ atmosphere for $15 \mathrm{~h}$. Isolated yields are reported. Diastereoselective ratio (dr) was determined by ${ }^{1} \mathrm{H}$ NMR spectroscopy after purification. [b] substrate allene $2 \mathrm{q}$ was retained under $50^{\circ} \mathrm{C}$ (see $\mathrm{SI}$ ). 
To check the practicability of this methodology, the alcohol 3a was prepared on a large scale. As shown in Scheme 2a, when the reaction was carried out with $1.0 \mathrm{mmol}$ of $1 \mathrm{a}$, the desired product 3a was obtained in $65 \%$ yield. The relative stereochemistry of 3a was determined to be anti-diastereomer by transformation into a known diol (Scheme 2b). ${ }^{[13]}$ After ozonolysis, 3a was converted to the diol $\mathbf{4 a}$, which was transformed to the acetonide $5 \mathbf{a}$ in $71 \%$ yield with $>95: 5$ $\mathrm{dr}$ (for details, please see the Supporting Information).

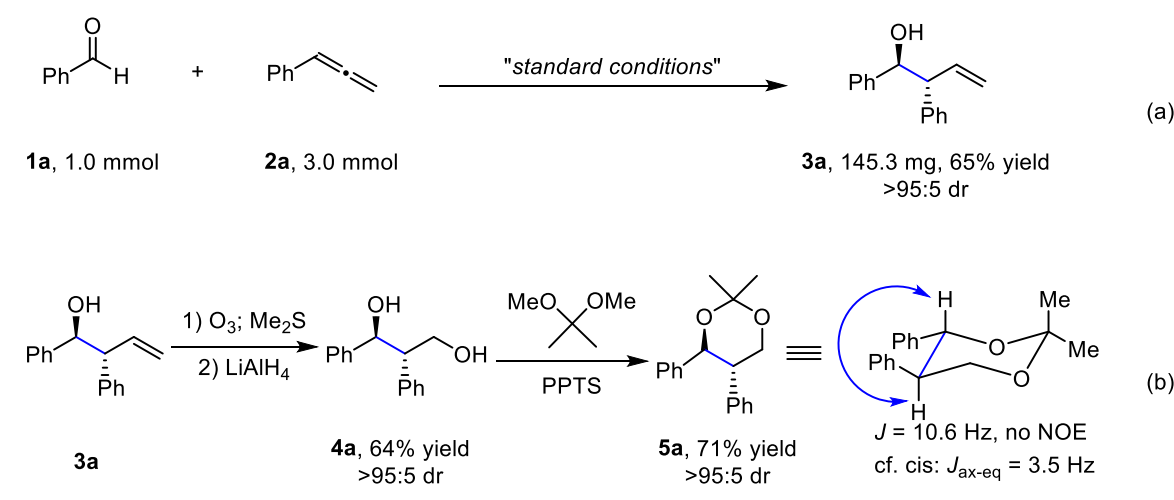

Scheme 2. Large scale reaction and relative configuration determination

To shed some light on the reaction mechanism, some control experiments were carried out (Scheme 3). Firstly, a radical clock study was performed with cyclopropane carbaldehyde 1ae under standard conditions, the corresponding product 3ae was formed, but no ring-opening product was observed (Scheme 3a). In addition, some representative radical scavengers such as TEMPO, 2,6-di-tert-butyl-4-methylphenol (BHT) and 1,1-diphenylethylene were examined with the model reaction (Scheme $3 b$ ). No significant influences were observed, indicating the absence of a ketyl radical intermediate generated through single electron transfer between photoexcited Hantzsch ester and aldehyde.[6a, 9a] Furthermore, a variety of deuterium scrambling experiments have been carried out with heavy water $\left(\mathrm{D}_{2} \mathrm{O}\right)$, deuterated $\mathrm{DCM}-d_{2}$, or deuterated allene substrate $\mathbf{2 a}-\boldsymbol{d}_{2}{ }^{[14]}$ (Scheme $3 \mathrm{c}$ ). These results clearly suggested that a nickel hydride species might be generated to a certain extent during the course of the reaction.

On the other hand, the light on/off experiment of the reaction was conducted, which suggested that a radical-chain propagation mechanism was not involved in the reaction (Scheme 3d), further supported by the quantum yield $0.39 \% .{ }^{[15]}$ To gain insight into interesting diastereoselectivity trends observed with aryl aldehydes, a Hammett plot of its para-substituent was constructed (Scheme 4e). ${ }^{[16]}$ Satisfactory correlations between $\mathrm{dr}$ and the electronic effects of the substituents were observed, which was similar to a recently reported allylation reaction catalyzed by cobalt ${ }^{[7 d]}$. We hypothesize that the aldehyde initially coordinates to nickel to provide a transient species, which via a selectivity determining Zimmerman-Traxler transition state undergo a preference of a pseudo-equatorial positioning of the aryl group of the aldehyde. ${ }^{[17]}$ Electron-rich aldehydes can accelerate this process by stabilizing positive charge build up on the $\mathrm{Ni}$-center during the transition state. 
(a) Radical clock experiment

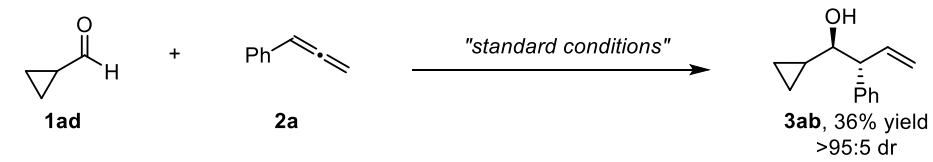

(b) Radical track experiment

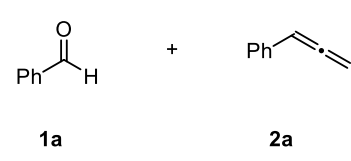

(c) H/D experiment
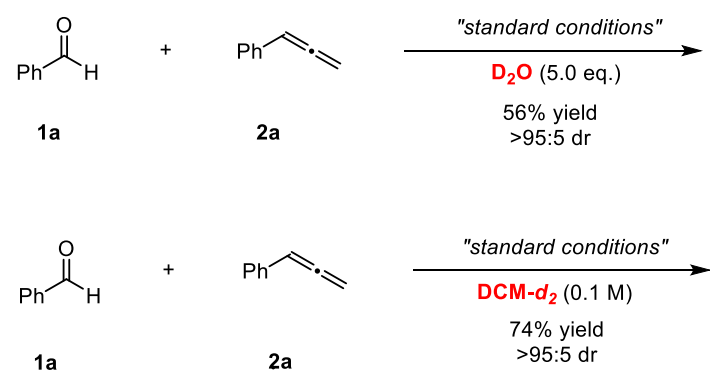

1a

2a

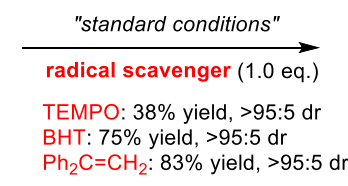

$\underbrace{\mathrm{OH}}_{\substack{\mathrm{P} h \\ \mathrm{Ph}}}$

$3 a$
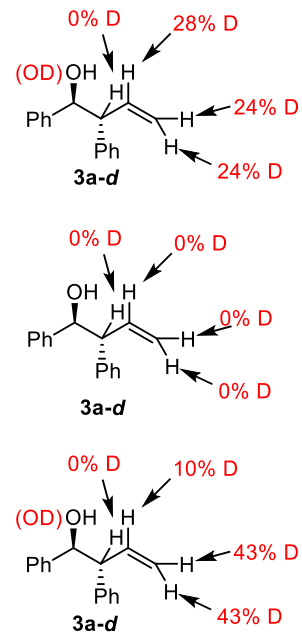

(e) Hammett plot analysis

(d)On/Off studies
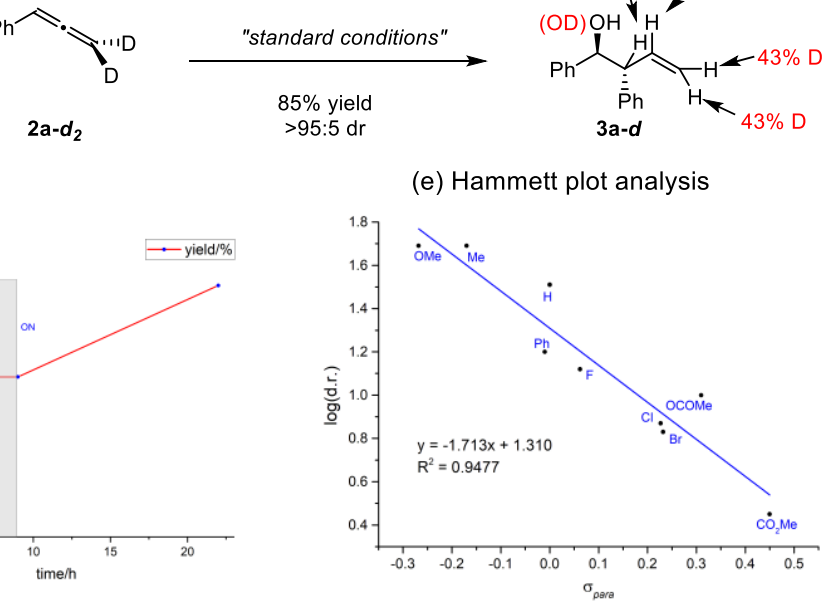

Scheme 3. Mechanistic studies

On the basis of the above obersavations and the previous reports ${ }^{[18]}$, a plausible reaction mechanism is proposed (Scheme 4). Firstly, irradiation of 4-CzIPN affords the excited 4-CzIPN*, which is reductively quenched by $\mathrm{HEH}$ leading to $4 \mathrm{CzIPN}^{--}$species ${ }^{[19]}$ and the corresponding Hantzsch ester radical cation $\left(\mathrm{HEH}^{\circ+}\right)^{[20]}$. Ligand coordinated $\mathrm{Ni}^{\prime \prime} \mathrm{Ln}_{n}$ species $\mathbf{I}$ is reduced to the low valent Ni'Ln intermediate II via single electron transfer (SET), ${ }^{[1]}$ which capturing the hydrogen from $\mathrm{HEH}^{+}$affords the pivotal nickel hydride $(\mathrm{Ni}-\mathrm{H})$ species III and pyridinium ion $\mathrm{PyH}^{+}$. Then, migratory insertion of the intermediate III to the allenes 2 generates the $\pi-$ allyInickel species IV, ${ }^{[22]}$ which further coordinates wyidith the aldehydes 1 to assemble the C$\mathrm{C}$ bonds furnishing the anti-homoallylic nickel alkoxide VI via a Zimmerman-Traxler transition state $\mathbf{V}{ }^{[17]}$ Protonation of the intermediate $\mathbf{V I}$ by $\mathrm{PyH}^{+}$would deliver the final product $\mathbf{3}$, and the pyridine compound $(\mathrm{PyH})$ which has been isolated as a byproduct. 


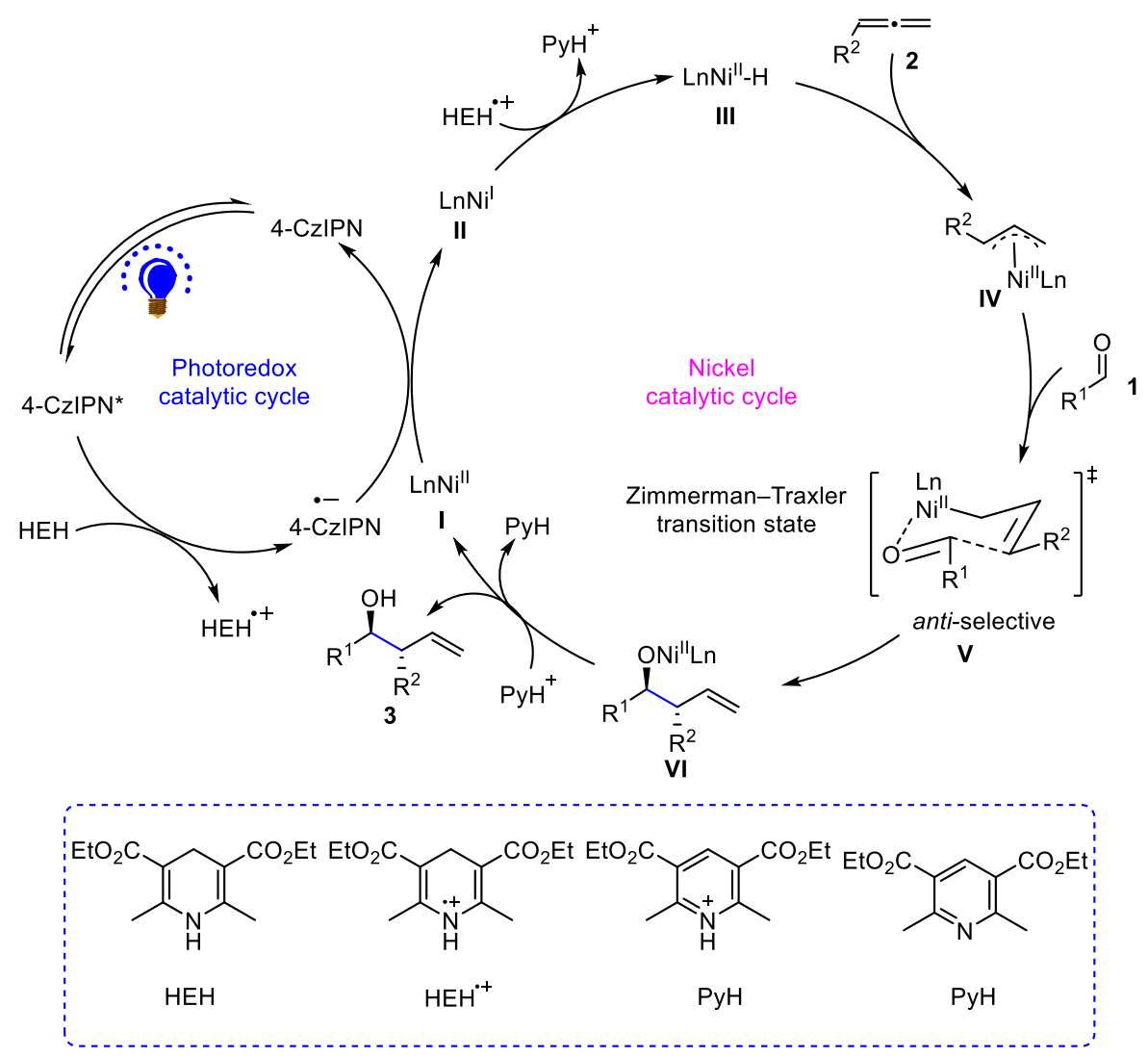

Scheme 4. Plausible reaction mechanism.

In conclusion, we have described a general, modular reductive for allylation of aldehydes upon coupling with allenes using a new organophotoredox/nickel dual catalysis process. Preliminary mechanistic studies indicate a key $\mathrm{m}$-allylnickel intermediate generated from $\mathrm{Ni}-\mathrm{H}$ insertion of allene: the coupling with an aldehyde occurs via a preferred Zimmerman-Traxler transition state, resulting in branch selective anti-homoallylic alcohols (up to $91 \%$ yield, $>95: 5 \mathrm{dr}$ ). This synthetic methodology has also provided a diverse way to access intermediates of medicinally relevant drugs. We hope that this novel methodology will complement and expand the field of metallaphotoredox catalyzed C-C bond forming reactions.

\section{Acknowledgements}

The authors gratefully acknowledge the Chinese Scholarship Council for a Ph.D. fellowship. Dr. Jun Zheng is thanked for the valuable discussion.

\section{Conflict of interest}

The authors declare no conflict of interest

Keywords: photoredox $\bullet$ nickel $\cdot$ allylation $\cdot$ homoallylic alcohol $\bullet$ allene

[1] For selected reviews on carbonyl allylation, see: a) M. Lombardo, C. Trombini, Chem. Rev. 2007, 107, 3843-3879; b) M. Yus, J. C. Gonzalez-Gomez, F. Foubelo, Chem. Rev. 2011, 111, 7774-7854; c) M. Yus, J. C. Gonzalez-Gomez, F. Foubelo, Chem. Rev. 2013, 113, 
5595-5698; d) I. P. Beletskaya, C. Najera, M. Yus, Chem. Rev. 2018, 118, 5080-5200; For selected syntheses of natural products containing a homoallylic alcohol moiety, see: e) Z. Lu, X. Zhang, Z. Guo, Y. Chen, T. Mu, A. Li, J. Am. Chem. Soc. 2018, 140, 9211-9218; f) K. C. Nicolaou, D. Rhoades, S. M. Kumar, J. Am. Chem. Soc. 2018, 140, 8303-8320; g) M. Schmid, A. S. Grossmann, K. Wurst, T. Magauer, J. Am. Chem. Soc. 2018, 140, 8444-8447.

[2] a) Y. Yamamoto, N. Asao, Chem. Rev. 1993, 93, 2207-2293; b) S. E. Denmark, J. P. Fu, Chem. Rev. 2003, 103, 2763-2793; c) D. Hall, Synlett 2007, 2007, 1644-1655; d) H.-X. Huo, J. R. Duvall, M.-Y. Huang, R. Hong, Org. Chem. Front. 2014, 1, 303-320; e) R. Guo, Q. Yang, Q. Tian, G. Zhang, Sci. Rep. 2017, 7, 4873-4884.

[3] For selected reviews on transition-metal-catalyzed allylation, see: a) M. Bandini, P. G. Cozzi, P. Melchiorre, A. U. Ronchi, Angew. Chem. Int. Ed. 1999, 38, 3357-3359; Angew. Chem. 1999, 111, 3558-3561; b) A. Fuerstne, Chem. Rev. 1999, 99, 991-1045; c) T. Tsuji, H. Yorimitsu, K. Oshima, Angew. Chem. Int. Ed. 2002, 41, 4137-4139; Angew. Chem. 2002, 114, 4311-4313; d) B. Trost, M., M. L. Crawley, Chem. Rev. 2003, 103, 2921-2943; e) X. Qian, A. Auffrant, A. Felouat, C. Gosmini, Angew. Chem. Int. Ed. 2011, 50, 10402-10405; Angew. Chem. 2011, 123, 10586-10589; f) G. Zhang, Q. Tian, Synthesis 2016, 48, 40384049; g) M. Holmes, L. A. Schwartz, M. J. Krische, Chem. Rev. 2018, 118, 6026-6052; h) K. Spielmann, G. Niel, R. M. de Figueiredo, J. M. Campagne, Chem. Soc. Rev. 2018, 47, 1159-1173; i) R. Blieck, M. Taillefer, F. Monnier, Chem. Rev. 2020, 120, 13545-13598; j) U. B. Kim, D. J. Jung, H. J. Jeon, K. Rathwell, S. G. Lee, Chem. Rev. 2020, 120, 13382-13433.

[4] a) I. S. Kim, M. Y. Ngai, M. J. Krische, J. Am. Chem. Soc. 2008, 130, 6340-6341; b) I. S. Kim, M. Y. Ngai, M. J. Krische, J. Am. Chem. Soc. 2008, 130, 14891-14899; c) M. Xiang, D. E. Pfaffinger, M. J. Krische, Chem.-Eur. J. 2021, 27, 13107-13116.

[5] For selected recent reviews on metallaphotoredox catalysis, see: a) J. Busch, D. M. Knoll, C. Zippel, S. Brase, C. Bizzarri, Dalton Trans. 2019, 48, 15338-15357; b) L. Pitzer, J. L. Schwarz, F. Glorius, Chem. Sci. 2019, 10, 8285-8291; c) P. Hünemörder, E. Mejía, Catal. Sci. Technol. 2020, 10, 6754-6768; d) D. W. C. MacMillan, E. D. Nacsa, in Organic Reactions, Vol. 100, Denmark, S. E. ed., John Wiley \& Sons, Inc., 2020; e) H.-H. Zhang, H. Chen, C. Zhu, S. Yu, Sci. China Chem. 2020, 63, 637-647; f) R. Cannalire, S. Pelliccia, L. Sancineto, E. Novellino, G. C. Tron, M. Giustiniano, Chem. Soc. Rev. 2021, 50, 766-897; g) H. Cao, X. Tang, H. Tang, Y. Yuan, J. Wu, Chem Catal. 2021, 1, 523-598; h) A. Y. Chan, I. B. Perry, N. B. Bissonnette, B. F. Buksh, G. A. Edwards, L. I. Frye, O. L. Garry, M. N. Lavagnino, B. X. Li, Y. Liang, E. Mao, A. Millet, J. V. Oakley, N. L. Reed, H. A. Sakai, C. P. Seath, D. W. C. MacMillan, Chem. Rev. 2021, DOI: 10.1021/acs.chemrev.1c00383; i) K. Donabauer, B. Konig, Acc. Chem. Res. 2021, 54, 242-252; j) A. Lipp, S. O. Badir, G. A. Molander, Angew. Chem. Int. Ed. 2021, 60, 1714-1726; Angew. Chem. 2021, 133, 17381750.

[6] a) J. L. Schwarz, F. Schafers, A. Tlahuext-Aca, L. Luckemeier, F. Glorius, J. Am. Chem. Soc. 2018, 140, 12705-12709; b) H. Mitsunuma, S. Tanabe, H. Fuse, K. Ohkubo, M. Kanai, Chem. Sci. 2019, 10, 3459-3465; c) S. Tanabe, H. Mitsunuma, M. Kanai, J. Am. Chem. Soc. 2020, 142, 12374-12381.

[7] a) A. Gualandi, G. Rodeghiero, A. Faraone, F. Patuzzo, M. Marchini, F. Calogero, R. Perciaccante, T. P. Jansen, P. Ceroni, P. G. Cozzi, Chem. Commun. 2019, 55, 6838-6841; b) A. Gualandi, G. Rodeghiero, R. Perciaccante, T. P. Jansen, C. Moreno - Cabrerizo, C. 
Foucher, M. Marchini, P. Ceroni, P. G. Cozzi, Adv. Syn. Catal. 2020, 363, 1105-1111; c) F. Schäfers, L. Quach, J. L. Schwarz, M. Saladrigas, C. G. Daniliuc, F. Glorius, ACS Catal. 2020, 10, 11841-11847; d) A. Cristofol, B. Limburg, A. W. Kleij, Angew. Chem. Int. Ed. 2021, 60, 15266-15270; Angew. Chem. 2021, 133, 15394-15398; e) C. Shi, F. Li, Y. Chen, S. Lin, E. Hao, Z. Guo, U. T. Wosqa, D. Zhang, L. Shi, ACS Catal. 2021, 11, 2992-2998.

[8] a) A. Gualandi, F. Calogero, M. Mazzarini, S. Guazzi, A. Fermi, G. Bergamini, P. G. Cozzi, ACS Catal. 2020, 10, 3857-3863; b) F. S. Li, Y. Q. Chen, S. J. Lin, C. Z. Shi, X. Y. Li, Y. C. Sun, Z. W. Guo, L. Shi, Org. Chem. Front. 2020, 7, 3434-3438; c) S. Potenti, A. Gualandi, A. Puggioli, A. Fermi, G. Bergamini, P. G. Cozzi, Eur. J. Org. Chem. 2021, 2021, 16241627.

[9] a) Y.-L. Li, W.-D. Li, Z.-Y. Gu, J. Chen, J.-B. Xia, ACS Catal. 2019, 10, 1528-1534; b) J. L. Schwarz, H.-M. Huang, T. O. Paulisch, F. Glorius, ACS Catal. 2019, 10, 1621-1627; c) F. Li, S. Lin, Y. Chen, C. Shi, H. Yan, C. Li, C. Wu, L. Lin, C. Duan, L. Shi, Angew. Chem. Int. Ed. 2021, 60, 1561-1566; Angew. Chem. 2021, 133, 1585-1590; d) Y. Q. Li, G. Chen, S. L. Shi, Org. Lett. 2021, 23, 2571-2577; e) S. Lin, Y. Chen, H. Yan, Y. Liu, Y. Sun, E. Hao, C. Shi, D. Zhang, N. Zhu, L. Shi, Org. Lett. 2021, 23, 8077-8081; f) L. Shi, S. Lin, F. Li, X. Li, Synthesis 2021, 53, 1889-1900.

[10]For selected reviews on nickel/photoredox dual catalysis, see: a) C. Vila, ChemCatChem 2015, 7, 1790-1793; b) L. N. Cavalcanti, G. A. Molander, Top Curr. Chem. 2016, 374, 3961; c) J. A. Milligan, J. P. Phelan, S. O. Badir, G. A. Molander, Angew. Chem. Int. Ed. 2019, 58, 6152-6163; Angew. Chem. 2019, 131, 6212-6224; d) C. Zhu, H. Yue, L. Chu, M. Rueping, Chem. Sci. 2020, 11, 4051-4064; e) S. Zhu, X. Zhao, H. Li, L. Chu, Chem. Soc. Rev. 2021, 50, 10836-10856; For selected recently reports on nickel/photoredox dual catalysis, see: f) J. K. Matsui, A. Gutierrez-Bonet, M. Rotella, R. Alam, O. Gutierrez, G. A. Molander, Angew. Chem. Int. Ed. 2018, 57, 15847-15851; Angew. Chem. 2018, 130, 16073-16077; g) N. A. Till, R. T. Smith, D. W. C. MacMillan, J. Am. Chem. Soc. 2018, 140, 5701-5705; h) J. Li, Y. Luo, H. W. Cheo, Y. Lan, J. Wu, Chem 2019, 5, 192-203; i) L. Zhang, X. Si, Y. Yang, M. Zimmer, S. Witzel, K. Sekine, M. Rudolph, A. S. K. Hashmi, Angew. Chem. Int. Ed. 2019, 58, 1823-1827; Angew. Chem. 2019, 131, 1837-1841; j) F. Song, F. Wang, L. Guo, X. Feng, Y. Zhang, L. Chu, Angew. Chem. Int. Ed. 2020, 59, 177-181; Angew. Chem. 2020, 132, 183-187; k) Y. Chen, K. Zhu, Q. Huang, Y. Lu, Chem. Sci. 2021, 12, 13564-13571; I) L. Zhang, S. Chen, H. He, W. Li, C. Zhu, J. Xie, Chem. Commun. 2021, 57, 9064-9067.

[11]a) S. S. Ng, T. F. Jamison, J. Am. Chem. Soc. 2005, 127, 7320-7321; b) S. S. Ng, T. F. Jamison, Tetrahedron 2005, 61, 11405-11417.

[12]a) P. Koschker, B. Breit, Acc. Chem. Res. 2016, 49, 1524-1536; b) A. M. Haydl, B. Breit, T. Liang, M. J. Krische, Angew. Chem. Int. Ed. 2017, 56, 11312-11325; Angew. Chem. 2017, 129, 11466-11480; c) H. M. Huang, P. Bellotti, F. Glorius, Chem. Soc. Rev. 2020, 49, 61866197; d) M.-M. Zhang, Y.-N. Wang, L.-Q. Lu, W.-J. Xiao, Trends in Chemistry 2020, 2, 764775.

[13]a) T. Aoyama, T. Eguchi, T. Oshima, K. Kakinuma, J. Chem. Soc. Perkin Trans. 1995, 1, 1905-1912; b) J. Pietruszka, N. Schöne, Eur. J. Org. Chem. 2004, 2004, 5011-5019; c) E. S. Schmidtmann, M. Oestreich, Angew. Chem. Int. Ed. 2009, 48, 4634-4638; Angew. Chem. 
2009, 121, 4705-4709; d) Y. Horino, M. Ishibashi, J. Sakamoto, M. Murakami, T. Korenaga, Adv. Syn. Catal. 2021, 363, 3592-3599.

[14]C. R. Woof, D. J. Durand, R. L. Webster, Chem.-Eur. J. 2021, 27, 12335-12340.

[15]D. Crich, X. Mo, S., J. Org. Chem. 1997, 62, 8624-8625.

[16]a) D. H. Mcdaniel, H. C. Brown, J. Org. Chem. 1958, 23, 420-427; b) C. D. Ritchie, W. F. Sager, Pro. Phys. Org. Chem. 1964, 2, 323-400.

[17]T. Mejuch, N. Gilboa, E. Gayon, H. Wang, K. N. Houk, I. Marek, Acc. Chem. Res. 2013, 46, 1659-1669.

[18]a) J. Zheng, B. Breit, Angew. Chem. Int. Ed. 2019, 58, 3392-3397; Angew. Chem. 2019, 131, 3430-3435; b) J. Zheng, A. Nikbakht, B. Breit, ACS Catal. 2021, 11, 3343-3350.

[19]H. Uoyama, K. Goushi, K. Shizu, H. Nomura, C. Adachi, Nature 2012, 492, 234-238.

[20]a) L. J. Rono, H. G. Yayla, D. Y. Wang, M. F. Armstrong, R. R. Knowles, J. Am. Chem. Soc. 2013, 135, 17735-17738; b) P. Z. Wang, J. R. Chen, W. J. Xiao, Org. Biomol. Chem. 2019, 17, 6936-6951; c) H. Guan, Q. Zhang, P. J. Walsh, J. Mao, Angew. Chem. Int. Ed. 2020, 59, 5172-5177.

[21]Q. Y. Meng, S. Wang, G. S. Huff, B. Konig, J. Am. Chem. Soc. 2018, 140, 3198-3201. S. A. S. W.Green, M. Crossley, J. L. M. Matos, S. Vásquez-Céspedes, S. L. Shevick, R. A. Shenvi, Acc. Chem. Res. 2018, 51, 2628-2640.

[22]M. Murakami, K. Itami, Y. Ito, Organometallics 1999, 18, 1326-1336. 